\title{
Recalibration of biochemistry measurements in a multinational cohort study: LIFE course study in CARdiovascular disease Epidemiology (LIFECARE)
}

\section{Ei Ei Khaing Nang ( $\nabla$ neekenator@gmail.com )}

National University of Singapore https://orcid.org/0000-0002-5361-0481

\section{Sheryl HX Ng}

National University Singapore Saw Swee Hock School of Public Health

\section{Mahham Shafiq}

National University Singapore Saw Swee Hock School of Public Health

\section{Chuen Seng Tan}

National University Singapore Saw Swee Hock School of Public Health

\section{Rody Sy}

College of Medicine, University of Philippines; Cardinal Santos Medical Center

\section{Alan Fong}

Clinical Research Centre, Sarawak General Hospital

\section{Prin Vathesatogkit}

Mahidol University Faculty of Medicine Ramathibodi Hospital

\section{John Adam}

Department of Medicine, Jaury Jusuf Putera Hospital, Faculty of Medicine, University of Hasanuddin

\section{Elmer Llanes}

College of Medicine, University of Philippines; Cardinal Santos Medical Center

Sim Kui Hian

Clinical research centre, Sarawak General Hospital

\section{Paul Reganit}

College of Medicine, University of Philippines, Cardinal Santos Medical Center

\section{Kung Yee Wong}

Clinical research centre, Sarawak General Hospital

\section{Mark Woodward}

The George Institute for Global Health, University of Sydney

\section{E Shyong Tai}

National University Singapore Yong Loo Lin School of Medicine

\section{Kavita Venkataraman}

National University Singapore Saw Swee Hock School of Public Health 
Research article

Keywords: recalibration, analytical variation, laboratory variation, biomarkers, cardiovascular diseases, Asia

Posted Date: June 3rd, 2020

DOI: https://doi.org/10.21203/rs.2.11061/v2

License: (c) (i) This work is licensed under a Creative Commons Attribution 4.0 International License.

Read Full License 
The authors have withdrawn this preprint from Research Square 